\title{
Analysis and standardization of landings per unit effort of red shrimp Aristeus antennatus from the trawl fleet of Barcelona (NW Mediterranean)
}

\author{
Valeria Mamouridis ${ }^{1}$, Francesc Maynou ${ }^{1}$, Germán Aneiros Pérez ${ }^{2}$ \\ ${ }^{1}$ Institut de Ciències del Mar, CSIC, Psg. Marítim de la Barceloneta 37-49, 08003 Barcelona, Spain. \\ E-mail: mamouridis@icm.csic.es \\ ${ }^{2}$ Facultade de Informática, Campus de Elviña s/n, Universidade da Coruña, 15071 A Coruña, Spain.
}

\begin{abstract}
Summary: Monthly landings and effort data from the Barcelona trawl fleet (NW Mediterranean) were selected to analyse and standardize the landings per unit effort (LPUE) of the red shrimp (Aristeus antennatus) using generalized additive models. The dataset covers a span of 15 years (1994-2008) and consists of a broad spectrum of predictors: fleet-dependent (e.g. number of trips performed by vessels and their technical characteristics, such as the gross registered tonnage), temporal (inter- and intra-annual variability), environmental (North Atlantic Oscillation [NAO] index) and economic (red shrimp and fuel prices) variables. All predictors individually have an impact on LPUE, though some of them lose their predictive power when considered jointly. That is the case of the NAO index. Our results show that six variables from the whole set can be incorporated into a global model with a total explained deviance (ED) of $43 \%$. We found that the most important variables were effort-related predictors (trips, tonnage, and groups) with a total ED of $20.58 \%$, followed by temporal variables, with an ED of $13.12 \%$, and finally the red shrimp price as an economic predictor with an ED of $9.30 \%$. Taken individually, the main contributing variable was the inter-annual variability $(\mathrm{ED}=12.40 \%)$. This high $\mathrm{ED}$ value suggests that many factors correlated with inter-annual variability, such as environmental factors (the NAO in specific years) and fuel price, could in turn affect LPUE variability. The standardized LPUE index with the effort variability removed was found to be similar to the fishery-independent abundance index derived from the MEDITS programme.
\end{abstract}

Keywords: LPUE; standardized LPUE; Aristeus antennatus; generalized additive models; NW Mediterranean; deep-water fisheries.

Análisis y estandarización de los desembarcos por unidad de esfuerzo de la gamba roja Aristeus antennatus por la flota de arrastre de Barcelona (Mediterráneo noroccidental)

Resumen: Se llevó a cabo un análisis del volumen de desembarcos por unidad de esfuerzo (LPUE) de la gamba roja (Aristeus antennatus) de la flota de arrastre en el puerto de Barcelona (Mediterráneo noroccidental) mediante modelos aditivos generalizados (GAM). El conjunto de datos cubre un periodo de 15 años (1994-2008) y consiste en un amplio espectro de predictores: variables dependientes de la flota (el número de mareas efectuadas por cada embarcación y las características técnicas de estas, como el tonelaje bruto), temporales (variabilidad inter- e intra-anual), ambientales (índice de Ocilación del Atlántico Norte [NAO]) y económicas (precio de la gamba roja y precio del combustible). Todos los predictores a nivel individual tienen impacto sobre LPUE, pero algunos de ellos pierden su poder explicativo cuando se considéran conjuntamente con otros, como en el caso del índice NAO. Nuestros resultados muestran que seis variables del conjunto pueden incorporarse en un modelo global con una desvianza total explicada $\mathrm{ED}=43 \%$. Las variables más importantes fueron aquellas relacionadas con el esfuerzo (número de mareas, tonelaje y grupos), con devianza $\mathrm{ED}=20.58 \%$, después las variables temporales, las cuales presentaron $\mathrm{ED}=13.12 \%$, y finalmentelos predictores económicos representados por el precio de la gamba con $\mathrm{ED}=9.30 \%$. A nivel individual, la variable con mayor contribución es la variabilidad inter-annual $(\mathrm{ED}=12.40 \%)$. Este elevado valor de devianza sugiere que muchos factores correlacionados con el tiempo pueden afectar la variabilidad de LPUE, como los factores ambientales (NAO en años particulares) y económicos, como el precio del combustible. La estandardización de LPUE con respecto al esfuerzo proporciona un índice de abundancia de la gamba roja muy parecido al índice de abundancia independiente de la pesquería obtenido mediante el programa de campañas experimentales MEDITS.

Palabras clave: LPUE; LPUE estandardizada; Aristeus antennatus; modelos aditivos generalizados; Mediterráneo noroccidental; pesquerías de profundidad.

Citation/Como citar este artículo: Mamouridis V., Maynou F., Aneiros Pérez G. 2014. Analysis and standardization of landings per unit effort of red shrimp Aristeus antennatus from the trawl fleet of Barcelona (NW Mediterranean). Sci. Mar. 78(1): 7-16. doi: http://dx.doi.org/10.3989/scimar.03926.14A

Editor: C. Froglia.

Received: July 23, 2013. Accepted: December 10, 2013. Published: March 7, 2014.

Copyright: () 2014 CSIC. This is an open-access article distributed under the Creative Commons Attribution-Non Commercial Lisence (by-nc) Spain 3.0. 


\section{INTRODUCTION}

Deep-water red shrimp is one of the main resources in Mediterranean fisheries in terms of landings and economic value (Bas et al. 2003), primarily in Spain and Algeria, where catches reach more than $1000 \mathrm{t}^{\text {year }}{ }^{-1}$ (FAO-FISHSTAT 2011). In the Mediterranean Sea, two red shrimp species, Aristeus antennatus and Aristaeomorpha foliacea, are caught by specialized trawl fleets operating on the upper and middle continental slope. The distribution of these two species varies geographically and in the NW Mediterranean catches are composed exclusively of $A$. antennatus (Bas et al. 2003).

The deep-water distribution of stocks extends to below 2000 m depth (Cartes and Sardà 1992) but commercial trawlers fish from 400 to $900 \mathrm{~m}$ depth. The red shrimp life-cycle includes seasonal, bathymetric and spatial migrations of different fractions of the population with great size and sex segregation: juveniles and small-sized males are more abundant in autumn and early winter in submarine canyons, while reproductive females concentrate on the open slope fishing grounds in late winter and spring (Sardà et al. 1997). This complex life cycle, coupled with a relatively long life span (more than 10 years according to Orsi Relini 2013) differentiates this species from tropical coastal shrimp resources elsewhere (Neal and Maris 1985).

The catches of $A$. antennatus show inter-annual fluctuations that have been related to environmental factors determining strong recruitment (Carbonell et al. 1999, Maynou 2008). Maynou (2008) suggested that winter NAO (North Atlantic Oscillation) is positively correlated with landings of $A$. antennatus two to three years later and that enhanced trophic resources for maturing females in winter and early spring result in stronger recruitments. The NAO has been demonstrated to be a pervasive environmental driver in other marine stocks elsewhere in the Mediterranean and Atlantic (e.g. Brodziak and O'Brien 2005, Dennard et al. 2010). However, the effect of technical and economic variables has received less attention. For instance, in the red shrimp fishery of the NW Mediterranean, Maynou et al. (2003) showed the importance of individual fisher behaviour in determining catch rates, and Sardà and Maynou (1998) discuss the effect of prices on changes of daily fishing effort targeting this species. Intra-annual variability in landings has been linked to market-driven variations in prices, which may result in changes in the fishing effort applied to the stocks, as the trawl fleet moves to alternative resources (Sardà et al. 1997).

Despite the commercial importance of A. antennatus in the Mediterranean (Sardà et al. 1997), deriving standardized catches or landings per unit effort (CPUE or LPUE) is not straightforward because of the lack of reliable time series at regional or subregional level (Lleonart and Maynou 2003). In fact, determining the abundance of marine stocks is notoriously a widespread problem (Hilborn and Walters 1992). Methodologies basically rely on two different data sources: fisheries-dependent or fisheries- independent data. Fisheries-dependent data tend to be the preferred source to assess the status of marine stocks (Lassen and Medley 2000) but since the applicability of these traditional assessment methods is limited when it comes to crustaceans, fisheriesindependent methods are usually preferred. However, fisheries-independent experimental trawl surveys in the western Mediterranean (Mediterranean International Trawl Surveys: MEDITS, Bertrand et al. 2002) are also problematic because they only partially cover the distribution depth range of $A$. antennatus. Thus, fisheries-dependent data are indeed used but methods that require age data are avoided and instead only regression style methods are used. For instance, in the Spanish Mediterranean sub-area 6 (ca. $1000 \mathrm{~km}$ long) just 4 to 12 trawl hauls are carried out annually in the 500-800 m depth stratum and none any deeper (Cardinale et al. 2012). Additionally, obtaining reliable landings including age information is problematic owing to difficulties in determining age in crustaceans (Orsi Relini et al. 2013). In these cases the information collected by a fishery is the main source of abundance data available (Maunder et al. 2006) and, when appropriately standardized, can be used to produce series of population abundance that should help fishery managers to promote the sustainable production of marine stocks.

Here, we evaluate the landings per unit effort from the daily sale slips provided by the Barcelona Fishers' Association from 1994 to 2008, corresponding to all the commercial transactions involving $A$. antennatus by a total of 21 trawlers operating on continental slope fishing grounds. The landings of A. antennatus have varied by almost an order of magnitude in this area in the last ten years, from a historical low of $13 \mathrm{t} \mathrm{year}^{-1}$ in 2006 to $96 \mathrm{t} \mathrm{year}^{-1}$ in 2012. Considering that the average ex-vessel price of the species in this period was $36 € \mathrm{~kg}^{-1}$ (among the highest seafood prices in Europe), these inter-annual fluctuations in landings have important economic consequences. Fisheries in Spanish Mediterranean waters are allowed between 50 and $1000 \mathrm{~m}$ depth for a maximum of 12 hours per day during daytime, except weekends. Hence, trawl skippers must decide which fishing grounds to visit taking into account that on the continental shelf they can be reached in a shorter time but will produce relatively cheap finfish, whereas deep-water fishing produces more valuable red shrimp but entails high economic costs and the risk of losing or damaging fishing gear.

The main objective of this study was to establish the factors influencing the LPUE (see e.g. Denis et al. 2002 for terminology) of A. antennatus in order to evaluate their relative importance (fishery-related, economic and environmental), which can be considered to manage effort constraints and to obtain a standardized series of LPUE as a reliable relative abundance index to assess natural abundance. We used generalized additive models (GAMs: Hastie and Tibshirani 1990) to capture the possible nonlinear dependence of LPUE on explanatory variables (Su et al. 2008, among others). 


\section{MATERIALS AND METHODS}

\section{Data source}

Trawlers from the Barcelona port operate on the continental shelf and slope fishing grounds (50-1000 $\mathrm{m}$ depth) located between $1^{\circ} 50^{\prime}$ and $2^{\circ} 50^{\prime}$ longitude east and 40 $50^{\prime}$ ' and 41 $30^{\circ}$ ' latitude north (Sardà et al. 1997). The fleet operates on a daily basis (with mandatory exit from port after 6 am and return to port before $6 \mathrm{pm}$ ) and a limited license system whereby total effort in the area has been frozen since 1986. New boats are only permitted if an existing boat is decommissioned. In addition to effort control, the only other measure of control is limiting mesh sizes (minimum $40 \mathrm{~mm}$ codend stretch mesh size) and neither in the study area nor in any other Mediterranean areas is there output control. Fish is auctioned daily at the premises of the port fish market and all transactions are recorded electronically for statistical purposes by the Barcelona Fishers' Association.

We used the daily sale slips containing all transactions of red shrimp (A. antennatus) over the period 1994-2008 to calculate the total monthly landings (kg month $^{-1}$, lands), the effort measured as total number of trips performed monthly by each vessel (number of trips per month, trips), and the monthly average exvessel shrimp price ( $€ \mathrm{~kg}^{-1}$, shprice). The same data set contained information on the engine power (horse power, $h p$ ) and gross registered tonnage (tons, grt), which we used as boat capacity indicators. As an indicator of fishing costs we used the average monthly fuel price $\left(10^{-3} € \mathrm{~L}^{-1}\right.$, fprice $)$ from the EUROSTAT website: http://ec.europa.eu/energy/observatory/oil/bulletin en.htm . As the environmental driver we used the NAO index, taken from the website of the Climate Analysis Group of the University of Exeter (UK): http://www1. secam.ex.ac.uk/cat/NAO. We considered: nao1, nao2 and nao3, corresponding to one, two and three years before the year of observed landings, using the significant time lags reported in Maynou (2008).

The response variable, lpue, was estimated as

$$
\text { lpue }=\frac{\text { lands }}{\text { trips }}
$$

hence, lpue is the monthly average landings of one vessel in each trip, corresponding to one fishing day $(\mathrm{kg}$ boat ${ }^{-1}$ day $^{-1}$ ), which will form the basis for providing a standardized abundance index.

To assess the individual effect of each vessel, a numeric variable code was assigned to each of the 21 vessels in the fleet. Each observation was attributed to a sequential time variable from January 1994 to December 2008 (180 months) and a month variable describing the month of the year. Two more variables were derived a posteriori from code and month, after checking for statistical differences among their categories in the model, and then by performing the Tukey Honest Significant Differences test (TukeyHSD). We thus derived the new variables, group and period, for code and month, respectively. The group variable combines the 21 trawlers into three groups of increasing lpue and period is a binary variable which classifies the months in "high effect" (period1: all months excluding June and November) and "low effect" (period2: June and November). All variables are shown in Table 1.

\section{Model construction}

We used generalized additive models, GAM, as described by Hastie and Tibshirani (1990)

$$
G(y)=x \beta+\sum s_{j}\left(x_{j}\right)+\varepsilon
$$

where $G(\cdot)$ is the link function, $y$ is the response variable, $x$ is the vector of linear predictors (explanatory variables), $\beta$ is the corresponding vector of parameters, $x_{j}$ are scalar predictors with unknown nonlinear effects represented by the functions $s_{j}(\cdot)$, and $\varepsilon$ is the random error.

The model building process consists of the following steps: 1) selection of the underlying distribution of the response (see Section 2.2.2 for more details); 2) selection of predictors building independent models for each covariant deleting insignificant effects in the final model; 3) selection between correlated predictors through the Pearson correlation coefficient (threshold value: $\rho=|0.6|$ ) to avoid problems of collinearity (Brauner and Shacham 1998) using the covariant with the most explanatory potential; and 4) analysis of residuals diagnostics.

\begin{tabular}{|c|c|}
\hline Variable & description (units) \\
\hline Ірие & landings per unit effort derived from lands and trips $\left(\mathrm{kg}\right.$ boat $\left.^{-1} \mathrm{day}^{-1}\right)$ \\
\hline lands & total monthly landings per vessel $\left(\mathrm{kg} \mathrm{month}^{-1}\right)$ \\
\hline time & time index of months, $t=1, \ldots, 180$, from Jan 1994 to Dec 2008 \\
\hline trips & number of trips performed by each vessel during the time $t$ \\
\hline$h p$ & engine power of vessels \\
\hline grt & gross registered tonnage of vessels \\
\hline shprice & red shrimp ex-vessel price $\left(€ \mathrm{~kg}^{-1}\right)$ \\
\hline fprice & fuel price one month before the observed lands $\left(10^{-3} € \mathrm{~L}^{-1}\right)$ \\
\hline nao $_{k}$ & mean annual NAO index, $k=1, \ldots, 3$ years before the year of observed lands \\
\hline month* $*$ & 12 categories corresponding to months \\
\hline period & 2 categories: period 1 , all months excluding June and Nov; period 2 , June and Nov \\
\hline $\operatorname{code} e^{* *}$ & 21 categories corresponding to a code assigned to each vessel \\
\hline group & 3 categories corresponding to groups of vessel \\
\hline
\end{tabular}

Table 1. - List of variables.

* Differences between pairs of categories of the variable month were checked through Tukey HSD test. Non-significantly different categories were grouped to create the new variable period, to which the same test was applied.

** The same procedure was applied for the variable code, to create the variable group (all significant tests with $p<0.001$ ). 
All analyses were performed in R3.0.1 (mgcvRpackage: Wood 2006). The generalized cross validation (GCV: Craven and Wahba 1979) and the outer Newton iteration procedure were used to estimate model parameters. GCV is preferable to the UBRE/ AIC method in the case of unknown smoothing parameters $\lambda$ (Wood 2006). Second order $P$-spline as defined by Marx and Eilers (1998) was used as a smoother for nonlinear functions.

\section{Theoretical response probability function}

Landings per unit effort are usually modelled following Gaussian or gamma distribution functions, often without formal justifications (Stefánsson 1996). Here, we assigned a theoretical probability function to the lpue, using nonparametric techniques described by Wassermann (2005). The density function, $f\left(y_{n}\right)$, was estimated using a histogram and the Gaussian kernel, where the $n r d$ described by Scott 1992 was the rule-ofthumb used to select the bandwidth.

The empirical cumulative distribution function, $F\left(y_{n}\right)$, and the $95 \%$ lower, $L\left(y_{n}\right)$ and upper, $U\left(y_{n}\right)$, confidence intervals were calculated as follows:

$$
\begin{aligned}
& F\left(y_{n}\right)=\left[\operatorname{rank}\left(y_{n}\right)-0.5\right] / N \\
& L\left(y_{n}\right)=\max \left\{F\left(y_{n}\right)-\varepsilon_{n}, 0\right\} \\
& U\left(y_{n}\right)=\min \left\{F\left(y_{n}\right)+\varepsilon_{n}, 1\right\},
\end{aligned}
$$

where $\operatorname{rank}\left(y_{n}\right)$ is the ranked vector of observations and $\varepsilon_{n}$ is the associated vector of errors resulting from the DKW (Dvoretzky-Kiefer-Wolfowitz) inequality

$$
\varepsilon_{n}=\sqrt{1 / 2 n \log _{e}(2 / \alpha)}
$$

The hypothesis tested is $\mathrm{H}_{0}: F\left(y_{n}\right)=F_{0}\left(y_{n}\right)$ versus the alternative hypothesis $\mathrm{H}_{1}: F\left(y_{n}\right) \neq F_{0}\left(y_{n}\right)$, where $F_{0}\left(y_{n}\right)$ is a theoretical function belonging to the exponential family, especially $F_{0}\left(y_{n}\right)=G a(a, b)$, the gamma distribution, whose density function is

$$
p(y) \propto y^{(a-1)} e^{(-b y)}
$$

for $y>0$. Parameters $a$ and $b$ are derived from the estimated expectation, $E(y)=a / b$, and variance $\operatorname{Var}(y)=$ $a / b^{2}$. Then the resulting distribution functions were graphically compared.

\section{Selection criteria and explained deviance}

Both AIC (Akaike 1973) and percentage of explained deviance (ED) were used as selection criteria: the selected model presented both the lowest AIC and the highest ED and all term parameters significantly different from zero.

The ED for each variable was also calculated in order to determine their relative importance in the final model. The residual deviance of the full model and the deviances of reduced models (i.e. the model excluding variable $x_{i}$ ) were calculated to derive the proportion explained by variable $x_{i}$ :
$\mathrm{DE} x_{i}=[D($ reduced model $)-D($ full model $)] / D($ null model $)$

where $D(\cdot)$ is the deviance for a given model and in the reduced model variable $x_{i}$ is omitted.

\section{LPUE standardization}

The model used for standardization was built in order to avoid dependency on fleet variables, maintaining environmental variables, which are expected to be related to the natural abundance of the species. The standardized LPUE is then

$$
\text { lpue }_{s t}=E(\text { lpue })+\left(\text { lpue }-E\left(\text { lpue }\left.\right|_{\Theta=\theta, \Lambda=\lambda}\right)\right)
$$

where lpue is the "nominal" or "raw" LPUE defined in Equation 1, E(lpue) is the unconditional expectation of the LPUE and E(lpue $\left.\left.\right|_{\Theta=\theta, \Lambda=\lambda}\right)$ is the conditional expectation of the LPUE given the vectors of parameters $\theta$ and $\lambda$, estimated using the appropriate standardization model.

Finally we compared our standardized LPUE with an alternative abundance index derived from fisheriesindependent data, available in the technical report SGMED-12-11 (Cardinale et al. 2012, pp. 136-150) after normalization of both variables.

\section{RESULTS}

\section{Overview of data and response distribution}

Figure 1 provides the raw lpue time series as reckoned in Equation 1 with its spline estimation (upper plot) and annual average of the NAO index (lower plot). The lpue series, initially constant, started to decline at the end of 1998 with a sharp maximum low in the period 1999-2000. Then the trend changed to inter-annual variation. Conversely, the NAO index shows the lowest records in the period 1995-1996. The lpue begins to decrease after three years from the first year of negative NAO. In Figure 2 the time series of the fuel price shows an increasing trend during the observed period (upper panel). The total number of trips per month performed by the whole fleet declines during the same period (middle panel), but it declines only at the beginning of the fuel price rise, then remaining almost constant (lower panel). Low lpue in the period 2000-2001 is also related to the peak of fprice in the same period (compare upper panels of Figs 1 and 2).

Characteristics of lpue are plotted in Figure 3. The probability density function $(p d f)$ is positively skewed (upper panels). Data hold atypical values in the right tail (see the box-plot, left middle panel) and the distribution function of the gamma distribution lies approximately inside the $95 \%$ confidence intervals of the empirical cumulative distribution function $(e c d f)$ of lpue (right middle panel). Finally, the QQ-plots for the gamma and the Gaussian distributions provide evidence of a better fit of data to the gamma rather than the Gaussian distribution (on the left and the right lower panels respectively). 

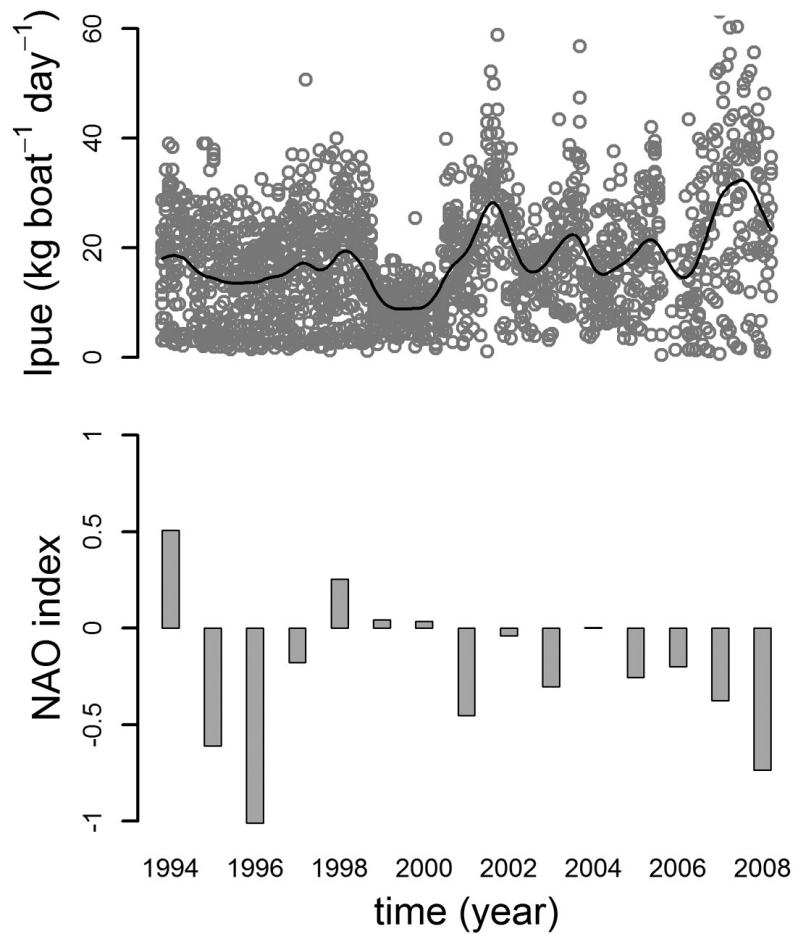

Fig. 1. - Time series from 1994 to 2008 of LPUE data and spline estimation (upper panel) and mean annual North Atlantic Oscillation (NAO) (lower panel).

\section{Model building and comparison}

The model building process is summarized in Table 2. All linear terms are reported before all smooth functions. Models are sorted in ascending order of total $\mathrm{ED}$, with the exception of models 11 and 12, corresponding to the GLM version of the final model 7 and the standardization model respectively. In comparison with the GLM (model 11), GAM's AIC decreases and the ED increases substantially (1.56 times), though the number of degrees of freedom increases considerably $\left(d f_{G A M}=27.7\right.$ versus $\left.d f_{G L M}=9\right)$. Variables $g r t$ and time were selected as better predictors than $h p$ and fprice, respectively, according to the Pearson correlation coefficients ( $g r t-h p$ was $\rho=0.61$; time-fprice $\rho=0.69$ ) and larger ED of former variables. All other correlations were $\rho<|0.6|$.

Table 2 incorporates the NAO terms, though their explanatory potential in the full model is too weak to be significant. Adding NAO terms to model 7 (Table 2: models $8,9,10$ ) did not improve model fit in terms of ED and AIC. Nevertheless, we found significant NAO effect in less complex models.

\section{The descriptive model}

The final model for $A$. antennatus LPUE is

$\log _{e}($ lpue $)=\theta+\alpha$ grt $+\beta$ period $2+\Sigma_{k=2,3}\left(\gamma_{k}\right.$ group $\left._{j}\right)$

$+s_{1}($ trips $)+s_{2}($ time $)+s_{3}($ shprice $)+\varepsilon$

where lpue $G a(a, b), \log _{e}$ is the link function, $\theta$ is the intercept, $\alpha$ is the parameter associated with the linear
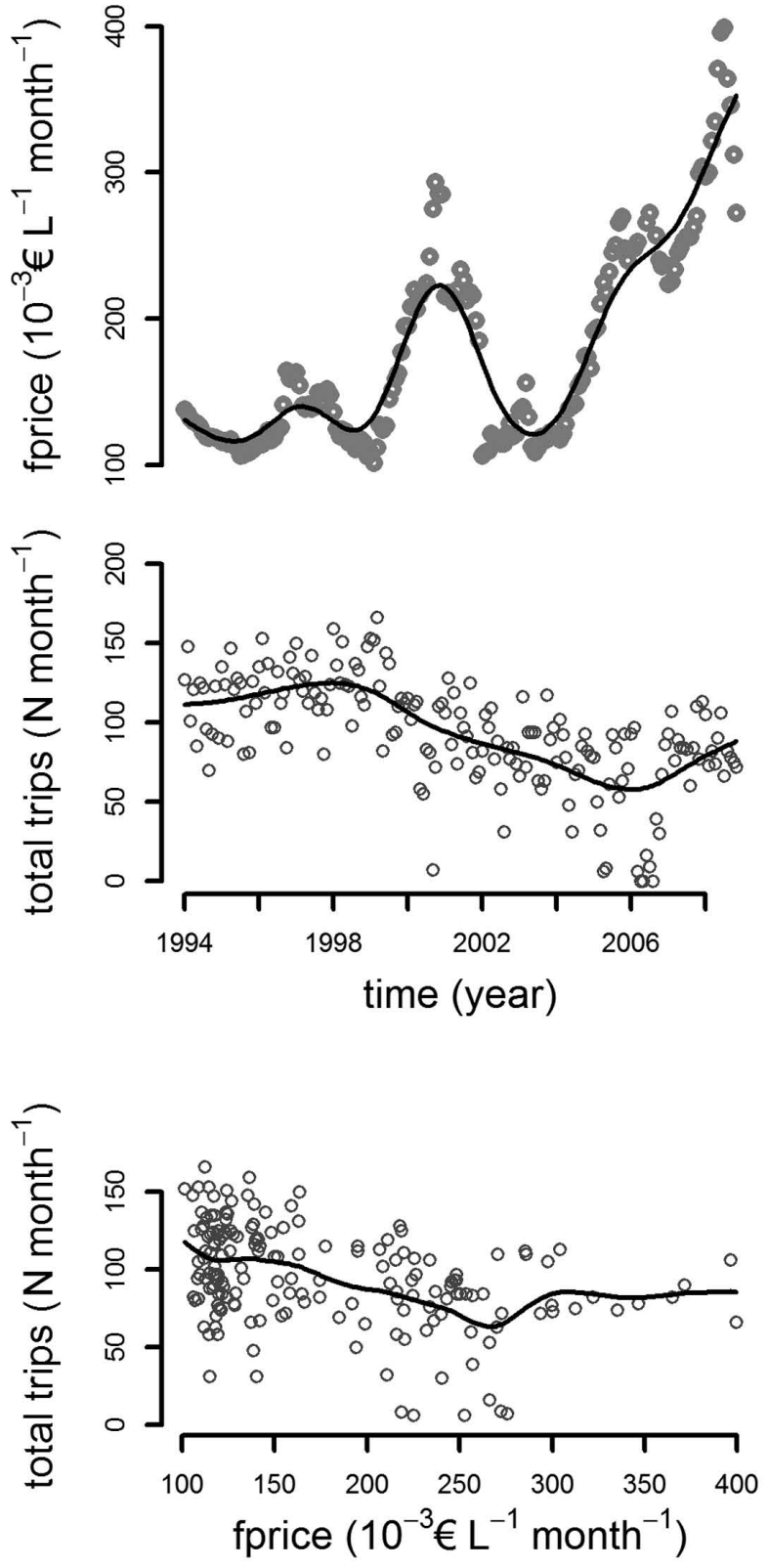

Fig. 2. - From top to bottom: spline estimation of the fuel price, monthly total number of trips performed by the fleet from year 1996 to 2008, and relationship between the fuel price and the total monthly number of trips.

effect of $g r t$, and $\beta$ and $\gamma_{k}$ are the effects associated with the categorical variables period and group. $s_{j}(\cdot)$ are the smooth functions associated with trips, time and shprice, while $\varepsilon$ represents the random errors of the model.

Figure 4 shows the diagnostic plots for the selected model. These plots show the results for the best model (corresponding to Equation 3 in the text and model 7 in Table 2). Residual quantiles lie on the straight line of the theoretical quantiles, although slightly heavytailed; in the histogram, residuals are consistent with normality and the relationship between response and fitted values is linear and positive. Residuals versus the linear predictor (that is, the sum of all partial effects) show a faint heteroscedasticity. 

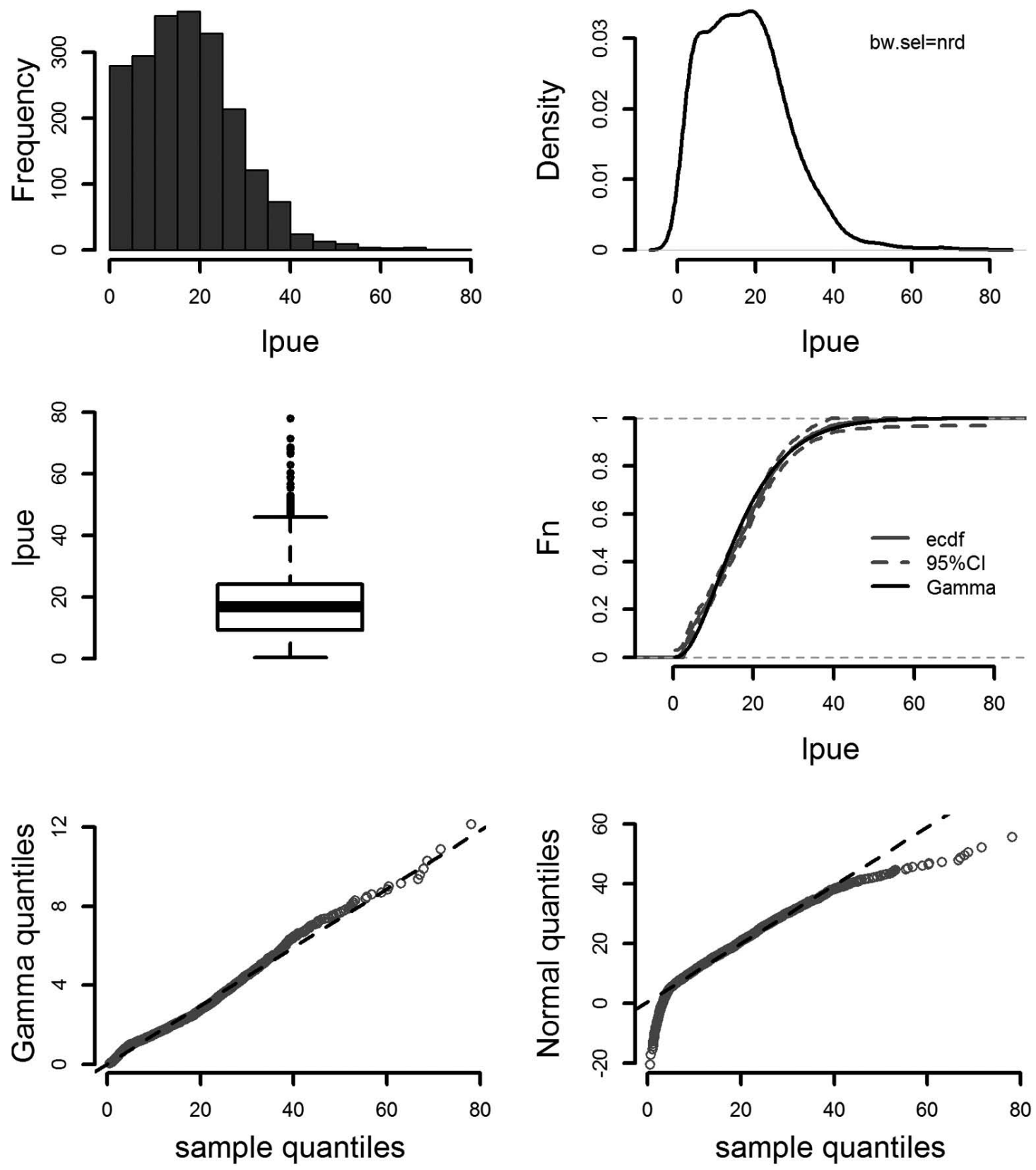

Fig 3. - From left to right, upper panels, histogram and kernel density estimations of lpue; middle panels, box-plot and cumulative distribution function of data and of the gamma distribution; lower panels, QQ-plots of sample quantiles versus gamma and normal distribution quantiles.

Table 2. - Model construction. $N$, number associated with each model; model, model's right part of the formula; $d f$, model's degree of freedom; RD, residual deviance, ED, percentage of deviance explained by each model; AIC, Akaike Information Criterion; term ${ }^{\text {(ns) }}$, insignificant terms in a model; term ${ }^{*}$, terms not incorporated in next steps (i.e. models with the incorporation of $h p$ or $f p r i c e$ gave a lower ED than the incorporation of grt and time, respectively). Model 12 is the model used for standardization.

\begin{tabular}{|c|c|c|c|c|c|}
\hline$N$ & model & $d f$ & $\mathrm{RD}$ & $\mathrm{ED}(\%)$ & AIC \\
\hline 1 & Int & 2 & 863.8 & 0 & 13544 \\
\hline 2 & $\operatorname{Int}+h p^{(*)}$ & 3 & 844.4 & 2.2 & 13501 \\
\hline 2.1 & Int + grt & 3 & 815.3 & 5.6 & 13432 \\
\hline 3 & Int + grt + group & 5 & 741.0 & 14.2 & 13250 \\
\hline 4 & Int + grt + group + period & 6 & 734.7 & 15 & 13235 \\
\hline 5 & Int + grt + group + period $+s($ trips $)$ & 8.9 & 627.8 & 27.3 & 12936 \\
\hline 6 & Int + grt + group + period $+s($ trips $)+s(\text { fprice })^{(*)}$ & 12.4 & 614.0 & 28.9 & 12900 \\
\hline 6.1 & Int + grt + group + period $+s($ trips $)+s($ time $)$ & 24.8 & 527.0 & 39 & 12632 \\
\hline 7 & Int + grt + group + period $+s($ trips $)+s($ time $)+s($ shprice $)$ & 27.7 & 493.5 & 43.0 & 12512 \\
\hline 8 & Int + grt + group + period $+s($ trips $)+s($ time $)+s($ shprice $)+s(\text { naol })^{(n s)}$ & 28.7 & 493.3 & 43.0 & 12513 \\
\hline 9 & Int + grt + group + period $+s($ trips $)+s($ time $)+s($ shprice $)+s($ nao 2$){ }^{(n s)}$ & 28.7 & 493.5 & 43.0 & 12514 \\
\hline 10 & Int + grt + group + period $+s($ trips $)+s($ time $)+s($ shprice $)+s($ nao 3$)(n s)$ & 28.7 & 493.4 & 43.0 & 12513 \\
\hline 11 & Int + grt + group + period + trips + time + shprice & 9 & 626.4 & 27.5 & 12932 \\
\hline 12 & Int + grt + code $+s($ trips $)$ & 24.75 & 608.7 & 29.5 & 12910 \\
\hline
\end{tabular}



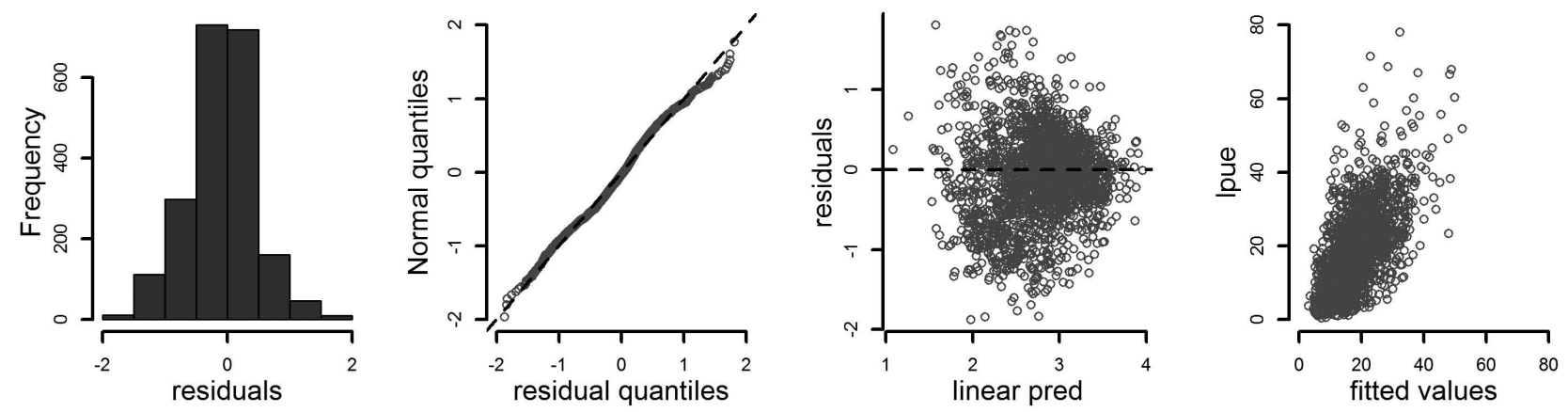

Fig. 4. - Residual diagnostics for model 7. From left to right: histogram and QQ-plot of deviance residuals; deviance residuals against linear predictor; response against fitted values.
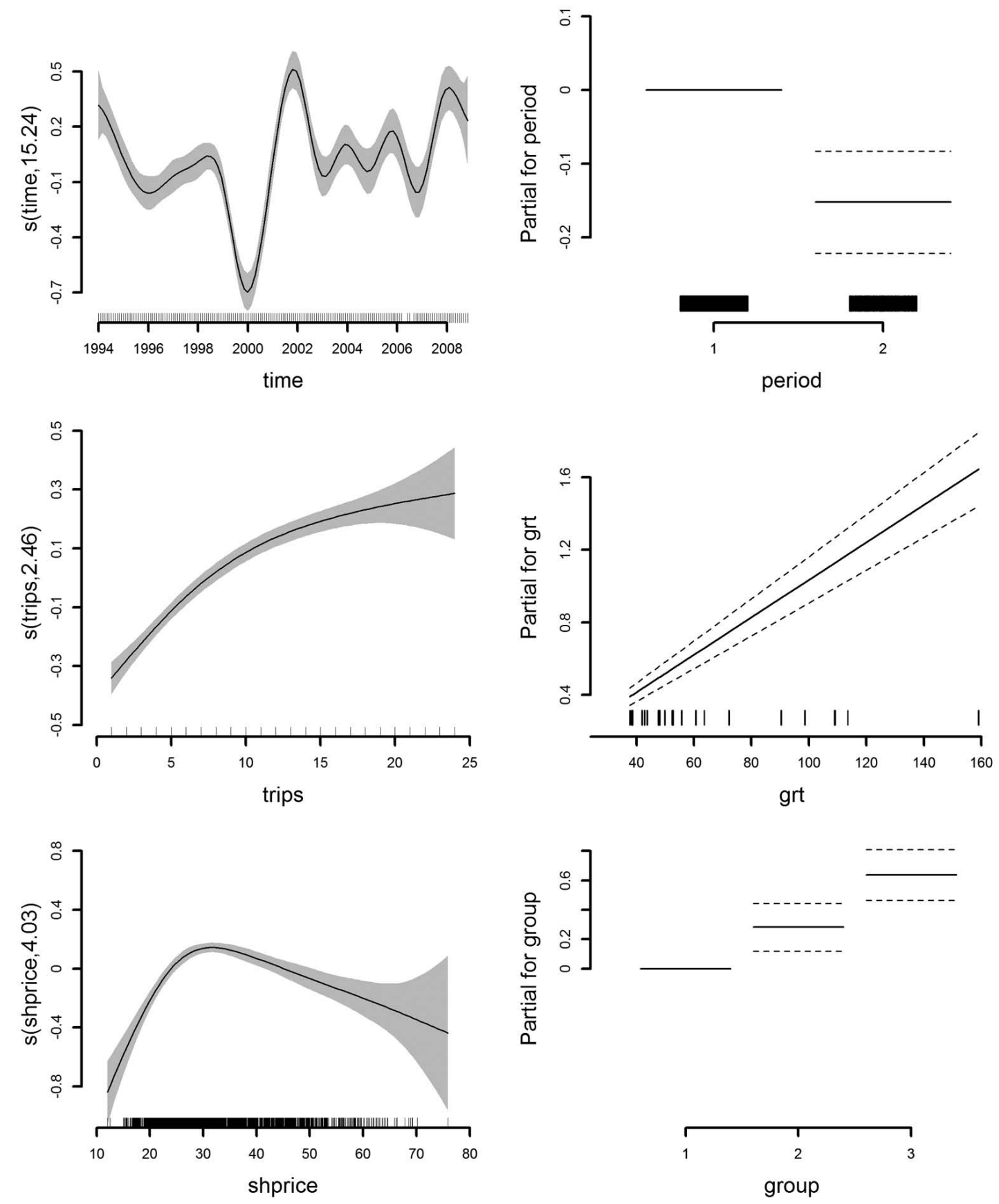

Fig. 5. - Partial effects of model 7. Bayesian credible intervals (95\%). 
Table 3. - Results of the final model (Eq. 3). Results associated with (a) linear terms, (b) smooth terms and (c) global estimations. Mean, estimation of the mean; std, standard deviation; $t$, value of $t$-statistic; $F$, the $F$ statistic value; $p$, p-value to the $t$ or the $F$ statistic; ED, percentage of deviance explained by each term; $e d f$, effective degrees of freedom; $\lambda$, estimated smoothing parameter; $d f$, total degree of freedom; $s c$, the scale parameter of the regression; $\mathrm{R}^{2}(\operatorname{adj})$, adjusted R-squared; AIC, Akaike Information Criterion; GCV, generalized cross validation; ED tot (\%), percentage of total deviance explained by the model.

\begin{tabular}{lccccc}
\hline (a) Linear terms & mean & std & $t$ & $p$ & ED $(\%)$ \\
\hline intercept & 1.746 & 0.103 & 16.980 & $<2 \mathrm{e}-16$ & 0 \\
period2 & -0.152 & 0.035 & -4.383 & $1.24 \mathrm{e}-05$ & 0.72 \\
group2 & 0.281 & 0.081 & 3.449 & $5.75 \mathrm{e}-04$ & 3.58 \\
group3 & 0.637 & 0.086 & 7.404 & $2.02 \mathrm{e}-13$ & \\
grt & 0.010 & 0.001 & 16.205 & $<2 \mathrm{e}-16$ & 5.62 \\
(b) Smooth terms & $e d f$ & $\lambda$ & $F$ & $p$ & $\mathrm{ED}(\%)$ \\
$s($ time $)$ & 15.239 & 0.011 & 24.82 & $<2 \mathrm{e}-16$ & 12.40 \\
$s($ trips) & 2.457 & 30.007 & 71.01 & $<2 \mathrm{e}-16$ & 11.38 \\
$s($ shprice $)$ & 4.026 & 0.059 & 26.36 & $<2 \mathrm{e}-16$ & 9.30 \\
(c) Global & & & & & \\
$d f$ & $s c$ & $\mathrm{R}^{2}(\mathrm{adj})$ & $\mathrm{AIC}$ & $\mathrm{GCV}$ & $\mathrm{ED} \mathrm{tot}(\%)$ \\
27.722 & 0.274 & 0.488 & 12512 & 0.282 & 43.00 \\
\hline
\end{tabular}

Table 3 shows results related to (a) the linear part, (b) the smooth functions and (c) the global parameters of the final model (Eq. 3), with a total explained deviance of $43.00 \%$. The predictor with the highest explanatory potential was time $(\mathrm{ED}=12.40 \%)$, which captured the intra-annual fluctuations in red shrimp, lpue. The second predictor in terms of explained deviance was trips $(\mathrm{ED}=11.38 \%)$. Red shrimp price was the third most important predictor $(\mathrm{ED}=9.30 \%)$. Other variables such as grt, group and period had less impact. The model returned all significant parameters $(\mathrm{p}<<0.001)$. All partial effects are reported in Figure 5. The partial effect for time shows a substantial difference before and after the period 1999-2000, when a clear drop is exhibited in the shape. Before this threshold the shape is almost constant, whereas after the abrupt decay increasing variation is observed over recent years. Predictor trips represents a positive and monotonic relationship, reaching a plateau for trips $>15$; shprice reached its maximum value around $30 € \mathrm{~kg}^{-1}$; lpue was significantly lower for period2, representing June and November, than for the rest of the year (period1). There were significant differences between the three groups of vessels. Variable grt showed a positive linear effect, meaning that larger vessels had higher lpue.

\section{LPUE standardization}

The model used to standardize A. antennatus LPUE is

$\log _{e}($ lpue $)=\theta+\alpha \operatorname{grt}+\sum_{j=2,21}\left(\gamma_{j}\right.$ code $\left.e_{j}\right)+s($ trips $)+\varepsilon$

where lpue $G a(a, b), \theta$ is the intercept, $\alpha$ the parameter for $g r t$ and $\gamma_{j}$ the effects associated with code. $s$ (trips) is the smooth function for trips and $\varepsilon$ the random errors. With the aim of standardizing, this model comprises all fleet-dependent variables, whose effect must be removed from the nominal value. The diagnostic plots show reasonably good outputs (not shown).

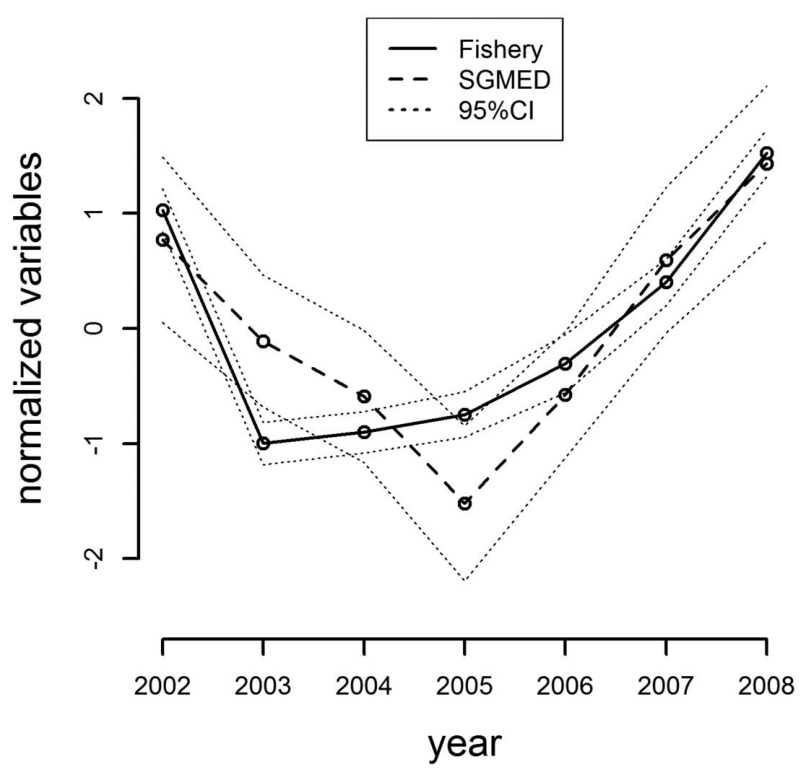

Fig. 6. - Comparison between the fishery-derived index (standardized LPUE) and the SGMED index. Variables have been normalized for comparison.

Finally, LPUE index and the SGMED in 2002-2008 with their confidence intervals after normalization of variables are plotted in Figure 6. The normalized Barcelona fishery's LPUE, calculated using Equations 4 and 2, has narrower confidence intervals than the normalized SGMED index. Only in 2004 were the two indices statistically different and in 2005 index estimates were at the limit of the other CI. Thus, five out of seven estimates can be considered equivalent.

\section{DISCUSSION}

This study presents models for relative abundance of $A$. antennatus harvested by one important Catalan fleet in the NW Mediterranean from 1994 to 2008. To our knowledge it is the first combined use of commercial fisheries data from Spain analysing environmental and economic variables with GAM techniques. Our objectives were: 1) to define the relative importance of predictors (model 7, Tables 2 and 3 ) and 2) to construct a standardized fishery-dependent index to compare with fishery-independent indices (Fig. 6). The results contribute to the identification of simple roles in red shrimp fishery management.

\section{The role of explanatory variables}

We incorporated effort, temporal, economic and environmental variables into a global regression model to evaluate their relative importance. Model 7 captures LPUE variability with a total deviance of $43 \%$ explained by six predictors. In order to quantify the different sources of LPUE variability, we found that the set of fishery-related variables (trips, grt and groups) was the most important source, with an ED of $20.58 \%$, followed by temporal (time and period, $\mathrm{ED}=13.12 \%$ ) and finally economic variables (shprice, $\mathrm{ED}=9.30 \%$ ). Among the variables taken from fishery 
data, trips has provided the greatest impact to date. A low number of trips per month could be associated with generalist trawlers operating usually on the continental shelf and with less knowledge about red shrimp fishing grounds than trawlers specialized in this fishery (Maynou et al. 2003), suggesting that the higher activity of non-specialized trawlers in deep-water harbours yields lower LPUE values (see Fig. 5: partial effect for trips). Conversely, boats performing a higher number of trips per month are expert in deep-water fishing grounds and their skippers are more likely to find highconcentration shoals through a process of trial and error (as hypothesized by Sardà and Maynou 1998). Boat characteristics ( $g r t$ ) also influence LPUE, as was to be expected. The greater the gross registered tonnage, the higher the LPUE that is observed. The variable group captures other capabilities of fishermen and technical characteristics of vessels, such as the type of engine, net shape and skipper's expertise, which have been shown to positively bias the LPUE (Maynou et al. 2003, Marriott et al. 2011) and are expected to be important in many fisheries (Maunder and Punt 2004). The importance of these predictors implies that their influence should be eliminated during standardization.

Inter-annual variable (time) is much more important than intra-annual variable (period) (Table 3). The former is more strongly determined by a range of sources, such as environmental and economic drivers, than the latter. The same order of importance was found by Maynou et al. (2003). The LPUE was almost constant before 1999-2000, when a sharp decline was observed. We hypothesized a relationship with low NAO in the previous three years (see Fig. 1 and the introduction) that confirms the findings of Maynou (2008) and a possible relationship with the increase in fuel prices beginning in 2000. The following years were characterized by high inter-annual variability, when the price of fuel increased and showed greater variations. We believe that the trend could be explained by economic factors (Fig. 2), especially since very high fuel-related costs are incurred in the fishing of red shrimp as a result of it being performed in deep-water (Sardà et al. 1997).

The partial effect of ex-vessel prices, shprice, shows a parabolic-like shape and significant explanatory potential $(\mathrm{ED}=9.30 \%)$. Low selling prices do not induce fishermen to practice this deep-water fishery, because they could not offset the high associated costs, and trawlers would rather switch to continental shelf fisheries, with lower costs and lower risk. When there are profits to be made, probably owing to the low availability of the product, fishermen practice this deep-water fishery more intensely and landings per unit effort also increase. At the higher sales price bracket (i.e. more than about $30 € \mathrm{~kg}^{-1}$ ) decreasing landing rates mean higher sale prices. Here, an alternation of cause and effect between the two variables probably comes into play. As mentioned, fprice is also an important explanatory variable, although it was not inserted in the final model because of its correlation with time. Fuel price has a significant effect on LPUE and can reach approximately $1.6 \%$ of explained deviance (as can be deduced from the model building process in Table 2).

\section{Implications for management}

Obtaining information on deep-sea species population dynamics is notoriously difficult, but our analysis suggests that the peculiarity of red shrimp fishery makes it possible to use fishery-dependent data to accurately describe the relative abundance of this resource. There are no discards for this fishery and the by-catch fraction, represented for example by Merluccius merluccius and Micromesistius poutassou, is small. These characteristics enable landings to be considered equivalent to catches and interchange LPUE and CPUE as indices (Hilborn and Walters 1992, Denis et al. 2002).

In turn, the definition of the relative importance of explanatory variables enables their impact on LPUE to be understood and makes intervention on the relevant variables possible from a management perspective. Fishery-related variables tend to have a significant effect on LPUE (ED=21\% in our case), and management measures aiming to reduce fishing mortality in this heavily harvested stock (Cardinale et al. 2012) could be based on limiting the size of the trawlers. Furthermore, the number of trips permitted in deep-water fishing grounds in this fishery could be limited, for example, by defining a threshold when the number of trips does not significantly increase the partial effect for LPUE (see Fig. 5).

In addition, to evaluate the impact of predictors on the LPUE, the regression analysis could be the basis to provide a standardized index for assessing species stocks. Standardization of landings data allows an index of the real species abundance to be developed, assuming that the explanatory variables available remove (or explain) most of the variation in the data that is not attributable to natural changes (Maunder and Punt 2004). We advocate the selection of effort predictors for standardization.

Trends in CPUE (and LPUE) are usually assumed to reflect changes in the abundance of marine stocks (Maunder and Punt 2004), but the raw index is often not proportional to abundance (Maunder et al. 2006). The raw LPUE is in fact dependent on many human factors that could be avoided. Time variables have a strong relationship with the abundance and environmental factors, which in turn are related to abundance, so they cannot be used in the model during standardization (e.g. see Maunder and Punt 2004). The economic source of variability should be considered, but shrimp price and LPUE realistically have a cause-effect relationship, so they could be not properly used. Conversely, fishery-related variables seem to be the most reliable for this purpose.

During the study period, the fleet was practically constant, making monthly trips a good indicator of fishing effort and landing ability, and remained almost constant despite potential technological creep (Marriott et al. 2011) because no significant changes in fishing technology have occurred in the area in the last 20 years.

Studies of deep-water systems, where harsh conditions limit methods for evaluating fisheries, often suffer from a lack of data in order to assess stock status. 
Although the goal of fisheries managers is to promote sustainable production of fish stocks through formal stock assessment, it is often impractical to collect fishery-independent data in isolated or harsh environments. In these cases the information collected by a fishery is the main (or only) source of abundance data available (Maunder et al. 2006).

\section{ACKNOWLEDGEMENTS}

The authors would like to express their sincere thanks to the Fisheries Directorate of the Government of Catalonia for giving access to the sales data of the Barcelona Fishers' Association, as well as to fishers of Barcelona. The first author is also very grateful to A. Rodríguez Casal and C. Cadarso Suárez for transmitting their knowledge in nonparametric statistics, to A. Gallen for revising the English and to M. Reyes for his suggestions on the manuscript. G. Aneiros is partly supported by Grant number MTM2011-22392 from the Ministerio de Ciencia e Innovación (Spain). Finally, this study was financed by the Spanish National Research Council (CSIC) through the JAE-predoc grant programme.

\section{REFERENCES}

Akaike H. 1973. Information theory as an extension of the maximum likelihood principle. In: Petrov B.N., Csáki F. (eds), Proc. 2nd Int. Symp. Information Theory, Akadémiai Kiadó, Budapest, pp. 267-281.

Bas C., Maynou F., Sardà F., Lleonart J. 2003. Variacions demogràfiques a les poblacions d'espècies demersals explotades: els darrers quaranta anys a Blanes i Barcelona. Inst. Est. Catalans. Arxiu de la Sec. Ciències, Barcelona.

Bertrand J.A., de Sola L.G., Papaconstantinou C., Relini G., Souplet A. 2002. The general specifications of the MEDITS surveys. Sci. Mar. 66: 9-17.

Brauner N., Shacham M. 1998. Role of range and precision of the independent variable in regression of data. Am. Inst. Chem. Eng. J. 44: 603-611. http://dx.doi.org/10.1002/aic.690440311

Brodziak J., O’Brien L. 2005. Do environmental factors affect recruits per spawner anomalies of New England groundfish? ICES J. Mar. Sci. 62: 1394-1407. http://dx.doi.org/10.1016/j.icesims.2005.04.019

Carbonell A., Carbonell M.S., Demestre M., Grau A., Montserrat S. 1999. The red shrimp Aristeus antennatus (Risso, 1816) fishery and biology in the Balearic Islands, western Mediterranean. Fish. Res. 44: 1-13. http://dx.doi.org/10.1016/S0165-7836(99)00079-X

Cardinale M., Osio G.C., Charef A. (eds). 2012. Report of the Scientific, Technical and Economic Committee for Fisheries on Assessment of Mediterranean Sea stocks - part 1. JRC Scientific and Policy Reports. European Commission.

Cartes J.E., Sardà F. 1992. Abundance and diversity of decapod crustaceans in the deep-Catalan sea (western Mediterranean). J. Nat. Hist. 26: 1305-1323. http://dx.doi.org/10.1080/00222939200770741

Craven P., Wahba G. 1979. Smoothing noisy data with spline functions: estimating the correct degree of smoothing by the method of generalized cross-validation. Numer. Mat. 31: 377-403. http://dx.doi.org/10.1007/BF01404567

Denis V., Lejeune J., Robin J.P. 2002. Spatio-temporal analysis of commercial trawler data using General Additive models: patterns of Loliginid squid abundance in the north-east Atlantic. ICES J. Mar. Sci. 59: 633-648

http://dx.doi.org/10.1006/jmsc.2001.1178
Dennard S.T., MacNeil M.A., Treble M.A., Campana S., Fisk A.T. 2010. Hierarchical analysis of a remote, Arctic, artisanal longline fishery. ICES J. Mar. Sci. 67: 41-51. http://dx.doi.org/10.1093/icesjms/fsp220

FAO-FISHSTAT. 2011. FAO Fisheries Department, Fishery information, Data and Statistics Unit. FishstatJ, a tool for fishery statistical analysis, release 2.0.0. FAO, Rome.

Hastie T., Tibshirani R. 1990. Generalized additive models. Chapman Hall, London.

Hilborn R., Walters C.J. 1992. Quantitative Fisheries Stock Assessment. Chapman \& Hall, New York. http://dx.doi.org/10.1007/978-1-4615-3598-0

Lassen H., Medley P. 2000. Virtual population analysis. A practical manual for stock assessment. FAO Fisheries Technical Paper. No. 400. FAO, Rome. 129 p.

Lleonart J., Maynou F. 2003. Fish stock assessments in the Mediterranean: state of the art. Sci. Mar. 67: 37-49.

Marriott R.J., Wise B., St John J. 2011. Historical changes in fishing efficiency in the west coast demersal scalefish fishery, Western Australia: implications for assessment and management. ICES J. Mar. Sci. 68: 76-86. http://dx.doi.org/10.1093/icesims/fsq157

Marx B.D., Eilers P.H.C. 1998. Direct generalized additive modelling with penalized likelihood. Comput. Statist. Data Anal. 28: 193-209. http://dx.doi.org/10.1016/S0167-9473(98)00033-4

Maunder M. N., Punt A. E. 2004. Standardizing catch and effort data: a review of recent approaches. Fish. Res. 70: 141-159. http://dx.doi.org/10.1016/j.fishres.2004.08.002

Maunder M. N., Sibert J. R., Fonteneau A., Hampton J., Kleiber P., Harley S.J. 2006. Interpreting catch per unit effort data to assess the status of individual stocks and communities. ICES J. Mar. Sci. 63: 1373-1385. http://dx.doi.org/10.1016/j.icesjms.2006.05.008

Maynou F. 2008. Environmental causes of the fluctuations of red shrimp (Aristeus antennatus) landings in the Catalan Sea. J. Mar. Sys. 71: 294-302. http://dx.doi.org/10.1016/j.jmarsys.2006.09.008

Maynou F., Demestre M., Sánchez P. 2003. Analysis of catch per unit effort by multivariate analysis and generalized linear models for deepwater crustacean fisheries off Barcelona (NW Mediterranean). Fish. Res. 64: 257-269. http://dx.doi.org/10.1016/j.fishres.2003.09.018

Neal R.A., Maris R.C. 1985. Fishing biology of shrimps and shrimplike animals. In: Provenzano A.J. (ed.) The Biology of Crustacea Vol 10: Economic aspects: fisheries and culture. Academic Press Inc.

Orsi Relini L., Mannini A., Relini G. 2013. Updating knowledge on growth, population dynamics, and ecology of the blue and red shrimp, Aristeus antennatus (Risso, 1816), on the basis of the study of its instars. Mar. Ecol. 34: 90-102. http://dx.doi.org/10.1111/j.1439-0485.2012.00528.x

Sardà F., Maynou F. 1998. Assessing perceptions: do Catalan fishermen catch more shrimp on Fridays? Fish. Res. 36: 149-157. http://dx.doi.org/10.1016/S0165-7836(98)00102-7

Sardà F., Maynou F., Talló L. 1997. Seasonal and spatial mobility patterns of rose shrimps Aristeus antennatus in the Western Mediterranean: results of a long-term study. Mar. Ecol. Prog. Ser. 159: 133-141. http://dx.doi.org/10.3354/meps159133

Scott D.W. 1992. Multivariate Density Estimation: Theory, Practice, and Visualization. Wiley, New York. http://dx.doi.org/10.1002/9780470316849

Stefánsson G. 1996. Analysis of groundfish survey abundance data: combining the. GLM and delta approaches. ICES J. Mar. Sci. 53: 577-588. http://dx.doi.org/10.1006/jmsc. 1996.0079

Su N.J., Yeh S.Z., Sun C.L., Punt A.E., Chen Y., Wang S.P. 2008. Standardizing catch and effort data of the Taiwanese distantwater longline fishery in the western and central Pacific Ocean for bigeye tuna, Thunnus obesus. Fish. Res. 90: 235-246. http://dx.doi.org/10.1016/j.fishres.2007.10.024

Wasserman L. 2005. All of Nonparametric Statistics. Springer, New York.

Wood S. N. 2006. Generalized Additive Models: An Introduction with R. CRC/Chapman Hall, Boca Raton, Florida. 